\title{
EL AUMENTO DE LA EDAD ORDINARIA DE JUBILACIÓN EN LA UNIÓN EUROPEA COMO MEDIDA PARA LA SOSTENIBILIDAD DE LOS SISTEMAS PÚBLICOS DE SEGURIDAD SOCIAL. UN FUTURO PROBLEMA TAMBIÉN EN BRASIL
}

\author{
THE RAISE OF THE ORDINARY AGE FOR RETIREMENT IN EUROPEAN UNION AS A \\ MEASURE FOR SUSTAINABILITY OF THE PUBLIC SOCIAL SECURITY SYSTEMS. A FUTURE \\ PROBLEM ALSO IN BRAZIL.
}

\section{Dr. José Ignacio García Ninet}

Catedrático de Derecho del Trabajo y de la Seguridad Social de la Universidad de Barcelona

\section{Jesús Barceló Fernández}

Investigador en formación del área de Derecho del Trabajo y de la Seguridad Social de la Universidad de Barcelona

Convidados

Recebido em:12.02.2016

Aprovado em:12.02.2016

DOI: $10.5585 /$ rdb.v12i5.346

\begin{abstract}
SUMARIO: I. INTRODUCCIÓN.- II. LAS DISTINTAS POLÍTICAS PARA HACER FRETE A LA SOSTENIBILIDAD DE LOS SISTEMAS PÚBLICOS DE PENSIONES.- III. LA REGULACIÓN DE LA EDAD DE JUBILACIÓN.- 1. Las primeras regulaciones de la edad de jubilación en los Seguros Obligatorios.- 2. El incremento en la edad ordinaria de jubilación.- IV. LA EDAD DE JUBILACIÓN EN LOS PAÍSES DE LA UE.- 1. La edad ordinaria de jubilación en los países de la UE.- 2. La posibilidad de prolongar el trabajo tras cumplir la edad ordinaria de jubilación en los países de la UE.- V. LA EDAD DE JUBILACIÓN DE BRASIL.1. Regulación de la edad de jubilación en Brasil.- 2. Futuras medidas relacionadas con la edad de jubilación.- VI. CONCLUSIONES.
\end{abstract}

\section{RESUMEN}

La reciente crisis económica y de deuda soberana enEuropa, junto al incremento del envejecimiento de la población, ha puesto de relieve los riesgos de sostenibilidad de los sistemas públicos de Seguridad Social y del Estado del Bienestar, tanto a corto, como a largo plazo. Los distintos Estados de la Unión Europea han abordado el problema de la sostenibilidad de distintas formas, pero en el futuro, el déficit público de las pensiones se extenderá al resto de países, sobre todo debido a las tensiones que provoca el envejecimiento de la población. Es importante analizar las distintas medidas que se están tomando en Europa para aprender de las exitosas y evitar repetir las que se hayan mostrado ineficientes o hayan 
causado perjuicios superiores a sus beneficios, entre cuyas medidas, el incremento en la edad de jubilación se muestra como una medida eficaz para la sostenibilidad financiera del sistema público de pensiones, sin suponer un perjuicio para los trabajadores en forma de reducción de la tasa de sustitución, que les aboque irremediablemente a la pobreza en su vejez.

PALABRAS CLAVE: Pensión de jubilación, sostenibilidad, edad de jubilación, Seguridad Social.

\begin{abstract}
The recent economic crisis and sovereign debt crisis in Europe, along with the increase of the aging population, it has highlighted the risks of sustainability of public system social security and of the welfare state, both short and long term. The different states of the European Union have addressed the issue of sustainability in different ways, but in the future, the public pension deficit will extend to other countries, mostly due to the tensions caused by the aging population.It is important to analyze the various measures being taken in Europe to learn from the successful measuresand prevent recurrence of the measures which have been shown ineffectiveor have caused greater damage that your benefits, among whose measures, the increase in the retirement age is shown as an effective measure for the financial sustainability of the public pension system, without being a detriment to workers which brings them to poverty in old age.
\end{abstract}

KEY WORDS: Retirement pension, sustainability, retirement age, Social Security.

\title{
INTRODUCCIÓN
}

El incremento de la esperanza de vida supone un incremento del envejecimiento de la población, lo cual es una mejora para la humanidad, pero a la vez supone un nuevo reto para los sistemas de Protección social, Sanidad y Pensiones, que deben enfrentarse a la sostenibilidad financiera del sistema de Seguridad Social.

A principios del año 2000, en las políticas de la UE se empieza a recomendar el incremento progresivo de la edad de jubilación y la prolongación de la vida activa de los trabajadores como medida de sostenibilidad económica de los sistemas públicos de Seguridad Social, y de solidaridad intergeneracional ${ }^{1}$, lo cual habría de suponer un incremento de la tasa de ocupación y, con ella, de los cotizantes a la Seguridad Social, a la vez que un descenso del número de pensionistas y, con éste, del coste de las pensiones. Por ello se señala que la sostenibilidad y adecuación de los sistemas de pensiones dependen en gran medida de las

${ }^{1}$ GARCíA NINET, José Ignacio. Acerca de la jubilación. Tribuna Social, Revista de Seguridad Social y Laboral. Número $152-153$. Valencia: 2003, p. 5. 
cotizaciones, los impuestos y del ahorro de los trabajadores. Por ello, es importante que exista un equilibrio entre cotizantes y beneficiarios de las pensiones ${ }^{2}$, para lo cual se debe promover la prolongación de la vida de trabajo, mediante la vinculación de la edad de jubilación al incremento de la esperanza de $v \mathrm{da}^{3}$, restringiendo el acceso a la jubilación anticipada ${ }^{4}$, creando las condiciones que permitan la elevación de la participación de las mujeres y los hombres en el mercado de trabajo a lo largo de sus vidasy el cierre de la brecha de pensiones entre hombres y mujeres ${ }^{5}$ y, junto a todo ello, mejorar las oportunidades para constituir planes de jubilación privados, complementarios a los seguros de jubilación ${ }^{6}$, aunque ello comporte sustanciales beneficiosos para la banca privada.

Por esta razón, con objeto de mejorar la sostenibilidad de las pensiones en la mayoríade países de la Unión Europea se han iniciado reformas de los sistemas públicos de pensiones, e incluso para garantizar que las tasas de reemplazo no se reduzcan, algunos Estados miembros de la UE han optado por complementar los sistemas de pensiones privados con planes de ahorro privados complementarios, aunque se reconoce que los planes de capitalización privados deberán ser más seguros y rentables, y compatibles con la flexibilidad y la movilidad de los mercados de trabajo ${ }^{7}$.

Actualmente, con las recientes reformas de los sistemas de pensionesla tasa de sustitución entre salario y pensión se verá reducida cada vez más ${ }^{8}$, sobre todo, en aquellos países en los cuales para garantizar la sostenibilidad se ha optado por aumentar el período de tiempo para tener derecho a la pensión de jubilación o para obtener el porcentaje máximo de la base de la misma, lo cual comprometerá la rentas de los pensionistas, acercándolos cada vez más al umbral de pobreza. Como adelanta la OCDE en su informe de $2013^{9}$, las recientes reformas de las pensiones de jubilación supondrán en el futuro que la mayoría de los trabajadores que ingresan hoy en el mercado de trabajo, se jubilarán a mayor edad, recibirán pensiones más bajas que las generaciones anteriores, y tendrán que ahorrar más para su jubilación, con el riesgo de caer en la pobreza que todo ello conlleva, salvo que se adopten medidas pensadas a favor de la clase trabajadora y no solo del gran capital.

\footnotetext{
${ }^{2}$ Libro Blanco. Agenda para unas pensiones adecuadas, seguras y sostenibles. Bruselas, de 16 de febrero de 2012. COM (2012) 55 final, p. 4.

${ }^{3}$ Ibídem, p. 10

${ }^{4}$ Ibídem, pp. 10, 11 y 12

${ }^{5}$ Ibídem, pp. 3, 7, 8, 10 y 13.

${ }^{6}$ Ibídem, p. 6, 10 y 14.

${ }^{7}$ Ibídem, p.6.

${ }^{8}$ Según los datos de la OCDE la tasa de sustitución de promedio en los países de la OCDE-34 era en 2011 de un $57,3 \%$, y en España se redujo del $81,2 \%$ antes de la reforma del 2011 a un 73,9\% tras ella. Por debajo de la media se encuentra Suecia con un 53,8\%, Francia con un $49,1 \%$, Alemania con un $42 \%$, Reino Unido con un 31,9\% y México con un 30,9\%. OCDE. Perspectivas OCDE: España Políticas para una Recuperación Sostenible. Octubre de 2011, p. 11.

${ }^{9}$ Pensions at a Glance 2013: Retirement-Income Systems in OECD and G20 Countries. http://www.oecd-

ilibrary.org/docserver/download/8113221e.pdf?expires=1385493298\&id=id\&accname=guest\&checksum=0C05ACFFA73AB5EA2BCBB98 43C98AF04
} 
El objetivo de este estudio es analizar las políticas de la Unión Europea y del Estado Español respecto al problema del envejecimiento de la población, centrándose en la prolongación de la vida activa del trabajador como finalidad en sí misma y como solución al problema de la sostenibilidad de las pensiones públicas de jubilación, pero sin olvidar lo que supone para la persona ese alargamiento de su vida activa cuando sus fuerzas ya van, día a día, flaqueando.

Además, concretamente, se pondrá en contraste con las políticas del Estado de Brasil, país que, junto a otros muchos, en un futuro no muy lejano deberá afrontar los mismos problemas que ahora padece la vieja Europa.

\section{LAS DISTINTAS POLÍTICAS PARA HACER FRETE A LA SOSTENIBILIDAD DE LOS SISTEMAS PÚBLICOS DE PENSIONES}

El interés y la preocupación por la sostenibilidad de las pensiones públicas no es un tema nuevo, éste es un problema que se ha venido advirtiendo por la propia Unión Europea desde mediados del siglo XX, aunque fue, sobre todo en la década de los ochenta y noventa, cuando ganó fuerza con el progresivo envejecimiento de la población y, consecuentemente, del número de pensionistas, y que ahora se ha visto revitalizado con la actual crisis económico/financiera, de la cual no son en absoluto culpables los que más directamente la están padeciendo. Consecuentemente, en los países de la Unión Europea y, en el futuro, en muchos otros países, como Brasil, las políticas que tienen como objeto asegurar la sostenibilidad de las pensiones públicas de jubilación ganan protagonismo ante el temor de que el envejecimiento de la población, la disminución de la población empleada, y el aumento del déficit público - sobre todo en los períodos de crisis-, hagan inviable el actual sistema público de pensiones.

Entre las medidas que los distintos estados de la Unión Europea han implementado, con el objeto de hacer sostenibles los sistemas públicos de Seguridad Social, se encuentran: $1^{\circ}$ ) incrementar el número de años que son necesarios para tener derecho a una pensión; $2^{\circ}$ ) endurecer los requisitos para tener derecho a lucrar el cien por cien de la pensión; $3^{\circ}$ ) establecer índices reductores de la cuantía económica inicial de la pensión; o $4^{\circ}$ ) controlar la revalorización de las pensiones existentes.

Todas estas medidas buscan controlar el déficit financiero del sistema de pensiones, aunque también tienen repercusiones negativas para los nuevos y actuales pensionistas, de distinto alcance según sea ésta. 
El equilibrio financiero del sistema de pensiones de jubilación depende de la diferencia entre ingresos y gastos de éste. Así, si los ingresos superan los gastos, el excedente sirve para dotar el fondo de reserva de las pensiones (cada día más mermado en España), que ha de servir para compensar los años en que sean los gastos los que superen a los ingresos. Por ello es necesario que las cantidades destinadas al fondo de reserva, en los años de superávit, superen a los déficits generados en los años en que el sistema sea deficitario.

Consecuentemente, para mantener el equilibrio financiero del sistema de pensionesse puede actuar tanto sobre los ingresos como sobre los gastos.

Incidir en los ingresos supone: $1^{\circ}$ ) contribuir para que aumente el número de cotizantes a la Seguridad Social; $2^{\circ}$ ) favorecer el incremento de los salarios, que tiene un efecto directo e inmediato en el incremento de las bases de cotización (así como en el consumo); $3^{\circ}$ ) incrementar los tipos de cotización, y/o $4^{\circ}$ ) aumentar las transferencias del Estado a través de sus Presupuestos Generales (lo cual depende de las sensibilidades sociales de los distintos gobiernos).

Respecto a la otra parte de la balanza, la reducción de los gastos en pensiones de jubilación supone: $1^{\circ}$ ) reducir la cuantía de la pensión media; $2^{\circ}$ ) limitar la revalorización de las pensiones de jubilación; o $3^{\circ}$ ) directamente, establecer un coeficiente reductor de la pensión de jubilación inicial.

Respecto a las reformas de los sistemas públicos de pensiones de reparto, éstas pueden ser paramétricas,en las cuales se mantiene la estructura y la filosofía del sistema de pensiones y sólo se introduce cambios cuantitativos, como puede ser: $1^{\circ}$ ) incrementar el periodo de cotización necesario para tener derecho a una pensión; $2^{\circ}$ ) aumentar el tiempo cotización para tener derecho a lucrar el cien por cien de la pensión; o $3^{\mathrm{a}}$ ) aumentar la edad de jubilación, sin vincularla al incremento de la esperanza de vida de la población.

Todas ellas suponen medidas fáciles de aplicar pero que son percibidas por la población como arbitrarias e impopulares, por ello en época electoral se vende un programa -escrito o no- que poco tiene que ver con el que después se aplica, echando las culpas a las supuestas herencias recibidas (pero muy conocidas cuando se está en la oposición) ${ }^{10}$.

Así, países como Alemania, Austria, Dinamarca, España o Francia, entre otros, han incrementado la edad de jubilación ordinaria, y otros han igualado progresivamente la edad de jubilación distinta entre hombres y mujeres (tema distinto es cuando en estos periodos se puede iniciar la vida laboral y en qué condiciones o con que tipos contractuales de mini-

${ }^{10}$ DEVESA CARPIO, José Enrique, et. al. El factor de sostenibilidad en los sistemas de pensiones de reparto: alternativas para su regulación en España. XV Encuentro de Economía Aplicada, celebrado en A Coruña los días 7 y 8 de junio de 2012. http://www.alde.es/encuentros/anteriores/xveea/trabajos/d/pdf/127.pdf. Consultado el 6 de julio de 2014, p. 8. 
empleos y mini-cotizaciones). Esta medida es impopular, ya que la edad de jubilación establecida tradicionalmente es percibida casi como un dogma el cual no puede ser alterado, sin plantearse que esta edad de jubilación debe estar fundamentada en la edad en que el trabajador ve mermada su capacidad para el trabajo debido a su avanzada edad -capacidad que ha mejorado con la mejora de la salud de la población de mayor edad-, y que ésta medida supone un ahorro para el sistema de pensiones, en forma de reducción del número de pensionistas, sin que suponga una reducción de la tasa de sustitución, incluso, viéndose mejorada al incrementarse los años cotizados o debido a la mejora de la base reguladora.

Otra medida adoptada, ha sido incrementar el número de años necesarios para poder lucrar el cien por cien de la base de la pensión de jubilación. Han sido los casos de Austria, Bélgica, España, Francia o Grecia. Ello supone un ahorro para los sistemas de pensiones en forma de reducción de la cuantía total agregada de las pensiones, pero a su vez reduce la tasa de sustitución de todos aquellos pensionistas con cortas carreras de cotización que no cuentan con los años necesarios para lucrar el cien por cien de la base reguladora (en la actualidad una gran cantidad de trabajadores a tiempo parcial).

Algunos países como Austria, España o Grecia también han incrementado el número de años a tener en cuenta para calcular la base de la pensión, llegando a computar la totalidad de la vida laboral, como es el caso de Grecia. Esta medida también supone una reducción de los gastos del sistema de pensiones, debido a que si se toma un mayor período para calcular la base reguladora, en la mayoría de los casos, supone computar bases de cotización más bajas, sobre todo, al incluir las bases de los primeros años en una profesión. Además, supone también computar mayores períodos con posibles lagunas de cotización, que dependiendo de si son integradas o no con las bases mínimas, supondrá un mayor número de años con bases de cotización en blanco. Todo ello repercute negativamente en la mayoría de los trabajadores en forma de menores bases reguladoras de la pensión.

Finalmente, algunos países han reformado los índices de revalorización de las pensiones, incorporando como índice el IPC (Austria), estableciendo un incremento por debajo del IPC a las pensiones más altas (Italia), o estableciendo un índice en el que se tiene en cuenta la variación del IPC y del PIB (Hungría). Con esta medida se pretende actualizar las pensiones al mismo nivel del incremento del IPC, o con otro índice económico más apropiado para medir la evolución de los precios de una Economía, como es el deflactor del PIB, ya que éstemide las variaciones de todos los bienes y servicios producidos en la economía en el periodo de referencia, en cambio, el IPC sólo mide los elementos de una cesta representativa de los bienes y servicios consumidos por los hogares, que dicho de paso, no representa la cesta 
de gastos de los pensionistas, los cuales tiene una cesta de gastos significativamente distintos a la población activa. Además, en muy pocos casos en que se utiliza el incremento de los salarios como medida indirecta del incremento de cotizaciones. En todo caso, actualizar las pensiones con el IPC, con el objeto de mantener el poder adquisitivo de los pensionistas, puede tener, como efecto negativo, el contribuir a la espiral de inflación en los momentos en que esta está disparada.

Por otro lado, las reformas no paramétricas son aquellas modificaciones del sistema de pensiones que supone un ajuste en el que lo futuros pensionistas pasan a soportar una parte del riesgo del envejecimiento de la población ${ }^{11}$, como pueden ser: $1^{\circ}$ ) la compatibilización de un sistema de reparto con una parte de sistema de capitalización; $2^{\circ}$ ) el cambio hacia el sistema de cuentas nocionales; o $3^{\circ}$ ) la vinculación automática de alguno de los parámetros relevantes del sistema de reparto a la evolución de la esperanza de vida o de la situación económica del país, como puede ser: a) la incorporación del factor de sostenibilidad; b) la incorporación del índice de revalorización de las pensiones, o c) el incremento automático de la edad de jubilación vinculada al aumento de la esperanza de vida.

Respecto a las fuentes de financiación, en la gran mayoría de los países de la Unión Europea $^{12}$ como Suecia, Bulgaria, Croacia, Estonia, Italia, Letonia, Lituania, Malta, Polonia, Eslovaquia, Eslovenia, u Holanda, tienen un sistema mixto, que combina un sistema contributivo - financiado por las aportaciones de las empresas y los trabajadores, completado, en algunos casos, con financiación obtenida de los impuestos--, con dos o más pilares de financiación de las prestaciones de jubilación ${ }^{13}$. En el caso de Suecia combinando un sistema de pensiones público de reparto, basado en el principio de cuentas nocionales; un sistema de capitalización complementario privado, con planes de pensiones ocupacionales; y un sistema universal, que protege de la pobreza a toda la población residentes,al menos 40 años en el país.Prácticamente, en el resto de países mencionados, como Bulgaria o Italia,se combina un sistema financiado con las contribuciones realizadas, con un fondo de pensiones profesional. Además, en todos los países es posible constituir una pensión financiada con aportaciones voluntarias a algún fondo de pensión privado de capitalización que, dependiendo del país, puede ser más o menos incentivados por los Estados mediante beneficios fiscales o de otro tipo.

\footnotetext{
${ }^{11}$ Ibídem, p. 9

${ }^{12}$ Datos extraídos del Sistemas de protección social - MISSOC. http://ec.europa.eu/social/main.jsp?catId=815\&langId=es. Consultado el 8 de julio de 2014.

${ }^{13}$ Los sistemas de pensiones pueden tener 3 o 4 pilares básicos: un primero no contributivo, solidario y de financiación pública, que proteja a toda la población de la pobreza en la vejez; un segundo pilar contributivo, obligatorio, público y de reparto; un tercer pilar obligatorio, de carácter profesional, privado y de capitalización; y un cuarto pilar voluntario, privado y de capitalización.
} 
En cualquier caso, la combinación de varios sistemas de financiación de las pensiones permite: $1^{\circ}$ )asegurar unas pensiones mínimas que protejan de la pobreza a la población en la tercera edad mediante los sistemas asistenciales o solidarios; $2^{\circ}$ ) reducir la presión sobre los sistemas contributivos, los cuales no precisan cubrir la totalidad de la pensión; y $3^{\mathrm{a}}$ ) complementar las pensiones de forma obligatoria o privada lo que, además, diversifica el riesgo inherente que supondría un sistema de capitalización puro.

Respecto al cambio de sistema, algunos países como Polonia, Letonia y Suecia instauraron un sistema de cuentas nocionales en la segunda mitad de la década de losnoventa.Este sistema también se basa en el reparto intergeneracional, sin embargo, es un sistema de aportación definida en el que el trabajador realiza aportaciones a esa cuenta nocional, calculándose su pensión de jubilación en función de lo aportado durante toda su carrera laboral, utilizándose reglas actuariales. Aunque el mayor problema lo supone la transición de un sistema a otro, especialmente en lo que se refiere a la atribución de cotizaciones y derechos ${ }^{14}$, y que deben existir otro tipo de pensiones que protejan de la pobreza a aquellos trabajadores que su cuenta nocional no les asegure unas rentas mínimas.

Otros países han instaurado mecanismos de ajustes automáticos vinculados a los cambio en la esperanza de vida de la población, incorporando sistemas de ajuste de la edad de jubilación, factores de sostenibilidad, o índices de revalorización de las pensiones.

Así países como Dinamarca, Italia, Grecia, Reino Unido u Holanda han aumentado la edad ordinaria de jubilación a la vez que han implementado el aumento automático de la edad ordinaria de jubilación vinculándola al aumento de la esperanza de vida en los futuros años, ajustándose cada 3 o cada 5 años. Algunos estudios indican que en el caso de España, vincular la edad de jubilación a la esperanza de vida supondría un incremento de la edad de jubilación de6 meses por cada 5 años, pasando de los actuales 67 años en 2027 a los 69 años en $2047^{15}$. Vincular el incremento automático de la edad ordinaria de jubilacióna los cambios en la esperanza de vida evita la inactividad de los partidos políticos ante el temor a que en las urnas se les castigue por esta medida impopular y, en cualquier caso, supone un ahorro para el sistema de pensiones, en forma de reducción del número de pensionistas, incrementado la población activa con el incremento de las expectativas de más años de vida y en mejores condiciones, y sin que suponga, a causa exclusivamente de esta medida, que la tasa de

\footnotetext{
${ }^{14}$ Grupo Consultivo de Reflexión sobre Políticas Públicas. Un sistema de cuentas nocionales para España. Por un sistema de pensiones solidario, sostenible y transparente. Abril de 2013. http://www.cen7dias.es/BOLETINES/413/informe_pensiones_413.pdf. Consultado el 6 de julio de 2014

${ }^{15}$ DEVESA CARPIO, José Enrique, et. al. op. cit., p. 22.
} 
sustitución se reduzca, sino que, bien al contrario, puede mejorarse al incrementarse los años cotizados o mejorar la base reguladora.

También algunos países, como Francia, han vinculado el incremento de la esperanza de vida al incremento del número de años necesarios para poder lucrar el cien por cien de la base de la pensión; y países como Italia lo vincula al incremento de los años necesarios para poder tener derecho a la pensión de jubilación. En ambos casos, la medida supone un ahorro en el gasto del sistema de pensiones, reducción que se consigue a costa de que los nuevos pensionistas que no consigan carreras completas de cotización y vean reducidas sus expectativas de nivel de rentas en su jubilación o, peor aún, un número importante de trabajadores puedan no llegar a obtener el derecho a una pensión contributiva, abocándoles al subsidio, en el mejor de los casos.

Por otro lado, el factor de sostenibilidad supone otro mecanismo de ajuste automático que vincula la cuantía inicial de la pensión de jubilación a la evolución demográfica. Los primeros países de la Unión Europea en implementarlo fueron Finlandia y Portugal, a los que siguió España ${ }^{16}$. Con el factor de sostenibilidad se pretende prevenir el riesgo de déficit del sistema de pensiones de jubilación que pueda causar el envejecimiento de la población a la vez que proporcionar unas pensiones equivalentes a las distintas generaciones, aunque hay que decir que esto último no forma parte del espíritu de un sistema de reparto, sino más bien de un sistema de capitalización, en el que el riesgo es compartido con los futuros pensionistas que verán reducida su pensión inicial debido a su mejora en la expectativa de vida, por tanto, vivir más años jubilados, pero con una cuantía de la pensión menor, lo cual comporta una menor calidad de vida, salvo que las distintas administraciones públicas prevean y provean a estos trabajadores-pensionistas de otros servicios o mejoras en especie para hacerles más llevaderos los últimos años de su existencia.

Respecto a la revalorización automática de las pensiones, Alemania y Suecia tienen distintos sistemas automáticos de revalorización, a los que hay que sumar el reciente índice de revalorización introducido en España ${ }^{17}$. En algunos casos se puede revalorizar en relación a los cambios en la renta media; en función a los cambios en los salarios medios; o, en función de la relación entre ingresos y gastos del sistema de pensiones,como es el caso de España, en donde la inflación es una referencia más a la hora de revalorizar las pensiones, pero no la más

\footnotetext{
${ }^{16}$ Ley 23/2013, de 22 de diciembre. Ley reguladora del Factor de Sostenibilidad y del Índice de Revalorización del Sistema de Pensiones de la Seguridad Social. BOE 26 diciembre 2013, núm. 309, [pág. 105137].

${ }^{17}$ También regulado en la Ley 23/2013, de 22 de diciembre; en el Capítulo IV de la Ley 22/2013, de 22 de diciembre. Ley de Presupuestos Generales del Estado para el año 2014. BOE 26 diciembre 2013, núm. 309, [pág. 104609; y en el Real Decreto 1045/2013, de 27 de diciembre. Revalorización de las pensiones del sistema de la Seguridad Social y de otras prestaciones sociales públicas para el ejercicio 2014. BOE 30 diciembre 2013, núm. 312, [pág. 106546].
} 
importante, porque también se tendrá en cuenta la evolución de la economía y el diferencial entre ingresos y gastos de la Seguridad Social.

Esta forma de revalorización automática de las pensiones, supone renunciar a la responsabilidad que le corresponde a los gobiernos de tomar la decisión sobre el incremento anual de las pensiones, no sólo en base a los datos macroeconómicos, sino también teniendo en cuenta otras circunstancias, sociales y de oportunidad, que aconsejen mantener o mejorar el poder adquisitivo de los pensionistas en cada momento, o incluso congelarlas si así está debidamente justificado; en este último caso, asumiendo el riesgo de impopularidad de la medida.

Como se ha podido ver, España ha adoptado, prácticamente, todas las medidas de sostenibilidad que han adoptado los distintos países de la Unión Europea, lo que supone incidir en distintos factores que intervienen en la sostenibilidad financiera de la Seguridad Social, aunque también supone asumir todos los efectos negativos de éstas, los cuales son padecidos por la población trabajadora. Otros países pueden seguir el modelo español o el de otros países de la Unión Europea, por ello el interés en estudiar las ventajas e inconvenientes de cada uno de ellos, o concretamente de aquel que se muestre como más conveniente, como probablemente sea utilizar únicamente la edad de jubilación como política que garantice la sostenibilidad del sistema de pensiones, que es la premisa en este trabajo.

En todo caso, es importante tener en cuenta el parámetro que se utilice para vincularlo a los cambios demográficos para conocer sobre qué colectivo va a recaer el riesgo. Así en el actual sistema de reparto de prestación definida el riesgo recae en los cotizantes, sin embargo, con los sistemas de ajuste automáticos pasa a ser soportado también por los actuales y futuros jubilados, lo que supone una medida de justicia intergeneracional ${ }^{18}$, aunque la eficacia en la sostenibilidad financiera de los sistemas públicos de pensiones, y la justicia intergeneracional no deben justificar que las pensiones se reduzcan a unos niveles que aboque a la pobreza a los pensionistas en el tramo final de sus vidas, tras haber contribuido con su trabajo a la economía, al crecimiento y al bienestar de la sociedad.

\section{LA REGULACIÓN DE LA EDAD DE JUBILACIÓN}

${ }^{18}$ DEVESA CARPIO, José Enrique, et. al. El factor de sostenibilidad en el sistema de pensiones español: regulaciones alternativas y efectos sobre los jubilados. Actuarios. Instituto de Actuarios Españoles. Número 31. Madrid: Otoño de 2012, p. 53. 
Sin perjuicio que existiera de antiguo distintas medidas de protección e las personas ante la pobreza en la vejez, las primeras regulaciones de Seguros Obligatorios de Vejez se dieron a finales del siglo XIX, los cuales fijaron, entre otros requisitos, una edad pensionable.

Las medidas anteriores a estos Seguros Obligatorios fueron medidas de gracia Real, de tipo paternalista por parte del empresario o de tipo asistencial, vinculándola a la pérdida de aptitudes para el trabajo por su avanzada edad, pero sin establecer una edad concreta, hasta que en el siglo XX se regularía la jubilación de funcionarios, o los Seguros obligatorios para los obreros.

Así, los Monarcas concedían subsidios de vejez a sus servidores públicoscomo recompensa asus buenos servicios. Entre otros, ya en 1714 se puede encontrar la jubilación por gracia del Rey del «Mayordomo Mayor de la Reina» y del «Caballerizo mayor de la Reina»,debido a los achaques y avanzada edad, manteniéndoseles el goce y honores de los $\operatorname{cargos}^{19}$; o en 1917 la concesión de la jubilación a un Alto mando del ejército por concesión Real $^{20}$; o en 1789 y 1799, la concesión por el Rey de la jubilación con derecho a la mitad del sueldo de algunos cargos públicos ${ }^{21}$.

Por otro lado, probablemente la primera norma que regula el derecho a la jubilación de los funcionarios en España ${ }^{22}$ fue la Real Orden de 23 de diciembre de 1776, la cual trató de atender al personal de resguardo de Madrid que, no pudiendo continuar desempeñando sus destinos por su edad, achaques u otros motivos calificados, solicitaban su jubilación. Posteriormente se ampliaría por Orden de 18 de febrero de $1803^{23}$ a todas las clases de dependientes de la Real Hacienda, concediéndose la jubilación aquellos que habiendo servido bien y fielmente, y cuando no puedan continuar el desempeño de su cargo por su edad, achaques u otros motivos, puedan jubilarse manteniendo la totalidad o parte del sueldo, dependiendo de los años de servicio. En otras ocasiones se delegaba en el Ministro la

\footnotetext{
${ }^{19}$ Madrid, 28 de Agosto de 1714.- El Rey nombró a la señora Marquesa de Aytona para que desde el Puerto donde desembarque la Reina se sirva hasta Madrid. Jubilación del Señor Conde de Sant-Esteban y del Marqués de Almonacir. El señor Marqués de Villa García, mayordomo del Rey partió a Bayona para informar a la Reina del casamiento del Rey con su sobrina la Princesa Doña Isabel Farnesio. Besamanos para el Príncipe el día de San Luis. Gaceta de Madrid núm. 35, de 28/08/1714, página 140.

${ }^{20}$ París, 30 de Agosto de 1717.- El Príncipe Eugenio vence el campo turco de Belgrado y se espera la victoria del sitio. El Agá turco se dirige a París. El Consejo de finanzas repite sus conferencias sobre el derecho de capitación y el diezmo de las rentas particulares. El Mariscal de Tesre obtiene gajes de jubilación por concesión real. Gaceta de Madrid núm. 37, de 14/09/1717, páginas 147 a 148.

${ }^{21}$ Madrid, 5 de Junio de 1789.- El Rey hizo varios nombramientos y concedió varios empleos. El Rey concedió la jubilación a los Intendentes del Ejército de Cataluña y Valencia. Gaceta de Madrid núm. 45, de 05/06/1789, página 396; y Madrid, 24 de diciembre de 1799. Nombramiento del Rey de diferentes cargos por vacante. Concesión de jubilación con la mitad del sueldo de D. Juan Francisco Juanicotona y nombramiento como Depositario General de Temporalidades a D. Francisco Manuel de Bodoya. Gaceta de Madrid núm. 103, de 24/12/1799, páginas 1096 a 1097.

${ }_{22}^{2}$ ESTEVE SEGARRA, María A. La Jubilación Forzosa. 1st ed. Tirant lo Blanch, 1999, P. 48.

${ }^{23}$ Real Orden tratando de atender a los empleados en la administración de la Real Hacienda que han servido bien y fielmente, y no pudiendo continuar desempeñando sus destinos por su edad, achaques u otros motivos calificados soliciten su jubilación, esta se amplíe a todas las clases de dependientes de Real Hacienda lo resuelto en 23 de Diciembre de 1776 con respecto a los del resguardo de Madrid, mandando en consecuencia que el que hubiese servido 30 años se le proponga con todo el sueldo que esté disfrutando, y disminuyendo según hayan trabajado menos años. Gaceta de Madrid núm. 14, de 18/02/1803, página 143.
} 
concesión de la jubilación de los cargos públicos, mediante Real Decreto ${ }^{24}$, e incluso mediante Decreto durante la $1^{\mathrm{a}}$ República $^{25}$, regulándose en 1868 los trámites que han de observarse en los expedientes relativos a jubilación de los empleados de carreras civiles, por causa de imposibilidad física ${ }^{26}$. Posteriormente, se reguló, a partir de 1905, la jubilación de todos los funcionarios al cumplir los 67 años, sin perjuicio de la facultad discrecional de los Ministros para jubilar a los funcionarios civiles del Estado, cuando estos cumplieran los 65 $\operatorname{años}^{27}$. También se pueden encontrar medidas como acuerdos de algunos Ayuntamientos para conceder pensiones de jubilación en recompensa de los buenos servicios de sus empleados ${ }^{28}$.

Por otro lado, los patronos también habían articulado distintas medidas de tipo paternalista, inspirados por motivos morales o religiosos ${ }^{29}$, para la protección de los obreros ancianos, a modo de lo que hicieran los antiguos gremios, cofradías o asociaciones similares. Recurriendo a instituciones mutualistas, cajas de retiros,seguros, cajas corporativas, o simplemente, adoptando el patrón de medidas como el traslado del trabajador anciano a un puesto de trabajo apropiado a su capacidad residual para el trabajo, o en caso de incapacidad absoluta, facilitando una pensión a través de una caja de previsión de aportación exclusiva de los patronos.

Las medidas asistenciales esotra forma de protección de la vejez que consiste en el pago por el Estado, sin ningún desembolso previodel obrero ni del patrono, de una pensión vitalicia a partir de ciertaedad y en determinadas condiciones.Este sistema se aplica inicialmente en Dinamarca, Nueva Zelanda, Australia, Francia e Inglaterra ${ }^{30}$. En España la encontramos en la creación en 1846 de hospitales de inválidos como el de la Real Armada para todo aquel miembro que se hallaba inutilizado para el servicio, incluida la «vejez achacosa», y que no pudiendo ganar su subsistencia, "encuentren asilo piadoso, merecido y honorífico" $^{\text {;1 }}$; o la declaración en 1908 de la Caja de Pensiones para la vejez y Ahorros, de

\footnotetext{
${ }^{24}$ Real decreto concediendo la jubilación que ha solicitado D. Francisco Olavarreita, Presidente del Tribunal Supremo de Justicia. Gaceta de Madrid núm. 715, de 17/12/1854, página 1; Real decreto concediendo jubilación a un Inspector general de primera clase del cuerpo de Ingenieros de Minas. Gaceta de Madrid núm. 81, de 22/03/1866, página 1; Real decreto concediendo su jubilación al Rector de la Universidad central. Gaceta de Madrid núm. 192, de 11/07/1866, página 1; o Decreto concediendo jubilación a un Catedrático de la Facultad de Medicina de la Universidad central. Gaceta de Madrid núm. 313, de 08/11/1868, página 3.

${ }^{25}$ Vid. Decreto concediendo jubilación á D. Isidro Sainz de Baranda, Inspector general de primera clase del cuerpo de Ingenieros de Minas. Gaceta de Madrid núm. 242, de 30/08/1874, página 533.

${ }^{26}$ Real Orden estableciendo los trámites que han de observarse en los expedientes relativos a jubilación de los empleados por causa de imposibilidad física. Gaceta de Madrid núm. 123, de 02/05/1868, página 1.

${ }^{27}$ Real Decreto de 2 de agosto de 1905; y Real decreto dictando reglas sobre jubilación, á los sesenta y siete años de edad, de todos los funcionarios dependientes de este Ministerio. Gaceta de Madrid núm. 33, de 02/02/1909, páginas 305 a 306.

28 Ley Municipal de 8 de enero de 1845; y Real decreto dictando prescripciones referentes a los acuerdos de los Ayuntamientos sobre conceder jubilación, socorros o pensiones individuales a los empleados del común y a sus viudas y huérfanos. Gaceta de Madrid núm. 129, de 09/05/1858, página 1.

${ }^{29}$ LÓPEZ VALENCIA, Federico. La acción patronal en el problema de los retiros obreros. Publicaciones del Instituto Nacional de Previsión. Madrid: 1913, p. 19.

${ }^{30}$ Ibídem, p. 20.

${ }^{31}$ Real decreto estableciendo un hospital de inválidos de marina con expreso destino a los que resultaren tales por heridas recibidas en combates, naufragios, incendios, faenas de mar, o por vejez achacosa contraída en constante y honroso servicio. Gaceta de Madrid núm. 494, de 28/04/1836, página 1.
} 
Barcelona, como una institución de la Beneficencia particular, la cual establece medidas de previsión social de la vejez, combinado ahorro y seguros ${ }^{32}$.

\section{Las primeras regulaciones de la edad de jubilación en los Seguros Obligatorios}

A finales del Siglo XIX, razones políticas como económicas ${ }^{33}$ llevan a algunos Estados a plantearse establecer medidas de protección de los trabajadores, inicialmente de naturaleza asistencial y muy ligada a la pobreza, para posteriormente configurarse como sistemas de seguro obligatorio para los obreros industriales, inspirado en el modelo del seguro privado.

La primera ley que regula una pensión de jubilación para los trabajadores de tipo contributivo, fue la Ley Alemana de «Seguro de invalidez y vejez» de 1889 impulsada por el Canciller Alemán Otto Van Bismarck, en la cual se fijaba la edad de retiro a los 70 años $^{34}$.

Posteriormente, la ley belga de 11 de Abril de 1900 fija la edad de retiro entre 55 y 65 años $^{35}$, y el 5 de Abril de 1910 se implanta en Francia el sistema alemán de seguro obligatorio, según el cual los trabajadores cuyo sueldo no llegara a 300 francos y no estuvieran sujetos al régimen de pensiones civiles o militares, disfrutaríande una pensión de vejez desde los 65 años, constituida por imposiciones obligatorias y potestativas de los asegurados, por cuotas de los patronos y por subvenciones del Estado ${ }^{36}$

En España, la ley de 27 de Febrero de 1908 implantó el sistema de libertad subsidiaria sobre bases análogas a la legislación belga y con la experiencia de los países en que estaba establecido. Para la práctica y difusión de los retiros obreros la ley crea el Instituto Nacional de Previsión ${ }^{37}$ que administra una caja de pensiones vitalicias diferidas, pagaderas desde los 55, 60 o 65 años, pudiendo anticiparse en caso de invalidez absoluta para el trabajo. Su constitución era voluntaria a favor de los trabajadores, los cuales realizaban ellos mismo, u otras en su nombre(entidades patronales o benéficas)y subsidiada por el Estado -de ahí que se

\footnotetext{
${ }^{32}$ Real orden declarando comprendida la Caja de Pensiones para la vejez y Ahorros, de Barcelona, en la categoría de instituciones de la Beneficencia particular. Gaceta de Madrid núm. 364, de 29/12/1908, página 1269; y Real orden declarando entidad similar del Instituto Nacional de Previsión a la Caja de Pensiones para la vejez y de Ahorros, de Barcelona. Gaceta de Madrid núm. 135, de 15/05/1909, páginas 1260 a 1261.

${ }^{33}$ Como señala DE LA VILLA GIL, Luís Enrique: el seguro social nace, sobre el modelo del seguro privado, con el objeto de desarmar la revolución social (razones políticas), y aumentar o mantener el poder adquisitivo de la clases obrera a la vez que su capacidad efectiva de trabajo (razones económicas). El principio de adecuación social y los conceptos jurídicos indeterminados en el Derecho del Trabajo. En: VV.AA. Los Principios del Derecho del Trabajo. Ed.: Centro de Estudios Financieros, Madrid: 2003.

${ }^{34}$ LÓPEZ VALENCIA, Federico. op. cit., pp. 24 y 35.

35 Ibídem, p. 28.

${ }^{36}$ Ibídem, p. 25.

${ }^{37}$ Ley referente a la organización por el Estado de un Instituto Nacional de Previsión. Gaceta de Madrid núm. 60, de 29/02/1908, páginas 875

a 876. El primer presidente del Instituto, D. Eduardo Dato, la definió como: “(...) un complejo problema de la política social contemporánea, reducido a una concisa fórmula actuarial”,
} 
denominara de "libertad subsidiada"38-, mediante imposicionesúnicas o periódicas, pudiendo hacerlo a capital cedido, es decir, sin derecho a ladevolución de las cantidades entregadas en caso de muerte, o a capital reservado, o sea devolviendo en caso de muertedel asociado a los herederos de éste las cantidades por él entregadasy las bonificaciones del Estado, patronos y particulares ${ }^{39}$.

Enel Congreso de Economía Nacional de Madrid del año 1917, el que fuera Director de Administración local Sr. Calvo Sotelo,propuso, en una ponencia que se estableciera el seguro obligatorio de vejez y se encargaradel mismo al Instituto Nacional de Previsión ${ }^{40}$.

En 1919, año que se abriría con la huelga de «La Canadiense» ${ }^{41}$, el Real Decreto de 11 de marzo de 1919, sobre el régimen de intensificación de Retiros obreros, creó el Régimen de Retiro obrero ${ }^{42}$; y el Real Decreto de 21 de enero de $1921^{43}$ lo implantó con carácter obligatorio. Según reconocía J. Maluquer -quien fuera el fundador del Retiro Obrero en España-, el retiro obrero obligatorio era una intensificación del seguro de vejez del régimen de libertad subsidiada ${ }^{44}$.

Posteriormente, se hizo una reforma sustancial del Retiro obrero, creándose el Subsidio de Vejez (Ley de 1 de septiembre de 1939, y órdenes reguladoras de 6 de octubre de 1939 y 2 de febrero de 1940). Este se concedía a los afiliados que tuvieran sesenta y cinco años de edad, siempre que aparecieran afiliados en el Régimen de Retiro antes del 1 de septiembre de 1939, y los inscriptos en el Subsidio. La insuficiencia y el carácter uniforme de este subsidio llevaron al desarrollo de un sistema complementario de carácter profesional ${ }^{45}$, a través del mutualismo laboral ${ }^{46}$, reduciéndose la edad de jubilación a los 60 años ${ }^{47}$, y la Ley de la Seguridad Social, de 21 de abril de 1966,fijaría nuevamente la edad de jubilación en 65 años ${ }^{48}$, aunque pudiendo rebajarse ésta por Decreto en aquellos trabajadores cuyos trabajos fueran de naturaleza excepcionalmente penosa, tóxica, peligrosa o insalubre y acusaran

\footnotetext{
${ }^{38}$ LÓPEZ VALENCIA, Federico. El ideario de Maluquer. Publicaciones del Instituto Nacional de Previsión. Madrid: 1934 , p. 79.

${ }^{39}$ VIGIL MONTOTO, Manuel. Los Retiros Obreros en España otros países. Publicaciones del Instituto Nacional de Previsión. Madrid: 1926, p. 12.

${ }^{40}$ MALUQUER Y SALVADOR, José. Aspectos sociales del retiro obrero. El régimen legal de retiro obrero significa una función pública de gran importancia para la clase trabajadora en la política social. Publicaciones del Instituto Nacional de Previsión. Madrid: 1924, p. 10.

${ }^{41}$ El 4 de febrero de 1919, la huelga iniciada originalmente en la empresa eléctrica «Riegos y Fuerza del Ebro S.A», empresa asociada a Barcelona Traction Light and Power, más conocida como «La Canadiense», se prolongó durante 44 días y paralizó casi toda la actividad industrial catalana, recordándose como un gran éxito del movimiento obrero.

${ }^{42}$ Real Decreto estableciendo el régimen de intensificación de Retiros obreros. Gaceta de Madrid núm. 71, de 12/03/1919, páginas 916 a 918

${ }^{43}$ Real Decreto por el que se aprueba el Reglamento general que se inserta, para la aplicación del Real decreto de 11 de Marzo de 1919 sobre intensificación del régimen de retiros obreros. Gaceta de Madrid núm. 23, de 23/01/1921, páginas 262 a 270.

${ }^{44}$ LÓPEZ VALENCIA, Federico. op. cit., p. 85.

${ }^{45}$ DE LA VILLA GIL, Luís Enrique y DESDENTADO BONETE, Aurelio. Manual de Seguridad Social. $2^{\text {a }}$ Edición. Editorial Aranzadi. Pamplona: 1979, p. 544.

${ }^{46}$ DECRETO de 10 de agosto de 1954 por el que se dictan normas reguladoras del Mutualismo Laboral. BOE núm. 256, de 13/09/1954, página 6179 .

${ }^{47}$ Art. 57. a) de la Orden de 10 de septiembre de 1954 por la que se aprueba el Reglamento General de Mutualismo Laboral. BOE núm. 260, de $17 / 09 / 1954$, páginas 6230 a 6250

${ }_{48}$ Artículo 150.1. a) del Decreto 907/1966, de 21 de abril, aprobado el texto articulado primero de la Ley 193/1963, de 28 de diciembre, sobre Bases de la Seguridad Social.
} 
elevados índices de morbilidad o mortalidad, y manteniéndose, transitoriamente, la edad de jubilación del mutualismo laboral.

Pero fue la Organización Internacional del Trabajo (OIT) la que en 1952 estableció en el artículo 26.2 del Convenio $102^{49}$, la generalización de la edad de 65 años, como edad que daba derecho a acceder a la prestación de vejez de la Seguridad Social, sin perjuicio de que pudiera fijarse una edad inferior, e incluso más elevada, teniendo en cuenta la capacidad de trabajo de las personas de edad avanzada en el país de que se trate, -que posteriormente en el artículo 15.2 del Convenio 128 de la OIT, amplia y completa con "criterios demográficos, económicos y sociales apropiados, justificados por datos estadísticos ${ }^{~}{ }^{0}$ - . Sin embargo, pese al intento de la OIT de uniformar la edad de jubilación ${ }^{51}$, el convenio 102 solo ha sido ratificado parcialmente por 50 países, algunos de los cuales como España o Irlanda no ratificaron la parte $\mathrm{V}$ sobre prestaciones de vejez, y posteriormente sólo 16 países ratificaron el Convenio 128.A pesar de ello la edad de jubilación a los 65 años se ha instaurado en la mayoría de los países prácticamente como un dogma, siendo está un elemento particularmente problemático en la regulación de los distintos sistemas de pensiones ${ }^{52}$.

Muy posiblemente la solución a la sostenibilidad del sistema público de pensiones no sea las reformas laborales o de Seguridad Social, sino la mejora de la competitividad de laeconomía mediante el incremento de la productividad ${ }^{53}$,pero si esto no es posible, sólo queda el camino de las reformas, aunque debieran implementarse aquellas que se muestren eficaces, a la vez que garanticen el estado del Bienestar.

\section{El incremento en la edad ordinaria de jubilación}

La Comunidad Económica Europea, en su Código Europeo de la Seguridad Social, de 16 de abril de 1964, mostraba su reticencia a establecer edades de jubilación superiores a los 65 años, salvo que el porcentaje de mayores de dicha edad no fuera superior al $10 \%$ de la población residente mayor de 15 años $^{54}$. Esta norma, en principio, tenía por objeto regular el

\footnotetext{
${ }^{49}$ Convenio 102 de la OIT, relativo a la norma mínima de la seguridad social. Adopción: Ginebra, $35^{\text {a }}$ reunión CIT (28 junio 1952). Ratificado por España las partes II, IV y VI, en fecha 29 de junio de 1988, lo que deja sin ratificar la parte V sobre prestaciones de vejez.

${ }^{50}$ Convenio 128 de la OIT, sobre las prestaciones de invalidez, vejez y sobrevivientes, 1967. Adopción: Ginebra, $51^{\text {a }}$ reunión CIT (29 junio 1967). Aunque, en este momento, sólo ratificado por 16 países, entre los que no se encuentra España.

${ }^{51}$ FERNÁNDEZ SÁNCHEZ, Sonia. Un estudio en torno a la edad de jubilación. Estudios de Progreso, 63/2011. Fundación Alternativas.

${ }^{52}$ DE LA VILLA GIL, Luís Enrique y DESDENTADO BONETE, Aurelio. op cit., p. 539.

${ }^{53}$ BELMONTE, 1. j., Corrales, A. J. y Ruiz, J. La sostenibilidad del sistema de pensiones en España. EuropeanJournal of Education and Psychology, Vol. 2, № 2, 2009, p. 127.

${ }_{54}$ Artículo 26 del Código Europeo de la Seguridad Social, de 16 de abril 1964, ratificado por Instrumento de 4 de febrero 1994 . BOE núm. 65/1995, de 17 de marzo de 1995.
} 
conflicto entre legislaciones, pero acabaría teniendo en la práctica una utilidad de verdadera norma de mínimos en materia de prestaciones de Seguridad Social ${ }^{55}$.

A pesar de ello, la Unión Europea ha sido siempre reticente a armonizar la edad de jubilación, como así señalaría el Comité Económico y Social ${ }^{56}$, el cual aceptó de la Comisión la propuesta de abstenerse de fijar una edad de jubilación uniforme, aunque estaba de acuerdo en que la edad de jubilación debía ser la misma para hombres y mujeres, evitándose así una diferencia discriminatoria.

Pero no fue hasta 1999 en que la Unión Europea se cuestiona por primera vez la posible adaptación de la edad de jubilación al aumento de la esperanza de vida ${ }^{57}$, sugiriendo que a los trabajadores de más edad se les deberá capacitar y motivar para que permanezcan más tiempo activos y se jubilen más tarde, reduciéndose así el coste de las pensiones ${ }^{58}$.

Posteriormente, la Comisión en $2005^{59}$, se propondrá la elevación de la edad en que se pone fin a la actividad ${ }^{60}$, el aumento de la edad media de retirada del mercado de trabajo ${ }^{61}$, y planteándose la conveniencia de seguir fijando una edad legal de jubilación, o permitir una jubilación flexible y progresiva ${ }^{62}$.Todo ello justificándose como medida para compensar la reducción prevista de la población en edad activa, lo cual debería producir un incremento de la participación de las personas de más edad en el empleo.

No obstante, la Comisión en $2006^{63}$, proponía fomentar el trabajo de las personas de más de 65 años, incluidas las que están formalmente jubiladas, aunque de forma totalmente voluntaria. En este sentido, ese mismo año, el Parlamento Europeo ${ }^{64}$ proponía introducir en las legislaciones de los Estados miembrosla posibilidad de que los trabajadores en edad dejubilación pudieran compatibilizar el cobro de una pensión de jubilación con la percepción del salario por el trabajo que realizan tras la jubilación, propuesta que suscribe el Comité Económico y Social Europeo ${ }^{65}$.

\footnotetext{
55 OJEDA AVILÉS, Antonio. La convergencia europea en materia de Seguridad Social: los problemas de un Código internacional de prestaciones mínimas. Revista del Ministerio de Trabajo e Inmigración, núm. 84, Madrid: 2009, P. 16.

${ }^{56}$ Dictamen sobre el proyecto de recomendación del Consejo relativa a los principios de una política comunitaria con respecto a la edad de jubilación. Diario Oficial de la CE no C 16 de 21 de enero de 1982, p.12.

${ }^{57}$ Comunicación de la Comisión: Hacia una Europa para todas las edades - Fomentar la prosperidad y la solidaridad entre las generaciones. Bruselas, 21 de junio de 1999. COM (1999) 221 final, p. 13

${ }^{58}$ Ibídem, p. 14.

${ }^{59}$ Comunicación de la Comisión Bruselas de 16 de marzo de 2005, Libro Verde «Frente a los cambios demográficos, una nueva solidaridad entre generaciones». COM (2005) 94 final.

${ }^{60}$ Ibídem, p. 4.

${ }^{61}$ Ibídem, p. 8 .

${ }^{62}$ Ibídem, p. 9.

${ }^{63}$ Comunicación de la Comisión de 12 de octubre de 2006: El futuro demográfico de Europa: transformar un reto en una oportunidad. COM (2006) 571 final, p. 10.

${ }^{64}$ Resolución del Parlamento Europeo sobre los retos demográficos y la solidaridad entre las generaciones (2005/2147(INI)). Diario Oficial $\mathrm{n}^{\circ} 292 \mathrm{E}$ de 01/12/2006 p. $0131-0140$, punto 57

${ }^{65}$ Dictamen del Comité Económico y Social Europeo sobre el tema «Libro Verde — En pos de unos sistemas de pensiones europeos adecuados, sostenibles y seguros». COM (2010) 365 final. (2011/C 84/08), punto 2.4.2.
} 
Pero no será hasta 2010, en que la Comisión ${ }^{66}$ reconoce que la prolongación de la edad de jubilación es una de las medidas para hacer frente a los principales retos que habrá de afrontarse con el envejecimiento demográfico, el cual puede llegar a producir una situación insostenible, salvo que, como propone, se trabaje más tiempo con el fin de que el gasto en pensiones no aumente a niveles inasumibles. Además, la Comisión añade que el equilibrio sostenible de las pensiones pasa por reconocer que cada vez se pasa más tiempo jubilado y esa proporción aumentará sustancialmente con el incremento de la esperanza de vida, salvo que la vida laboral se prolongue y el momento de la jubilación se posponga.

Consecuentemente, propone aumentar la edad a la que se deja de trabajar y se empieza a cobrar una pensión, adoptándose una medida que se han demostrado prometedora para fortalecer la sostenibilidad de los sistemas de pensiones,como es un ajuste automático de la edad de jubilación ${ }^{67}$, que consiste en aumentar la edad de jubilación en consonancia con el futuro aumento de la esperanza de vida. También propone adoptar otra medida ya probadas por algunos Estados miembros, ${ }^{68}$ como es la combinación de medidas para aumentar la edad de jubilación con medidas que incrementan el número de años de cotización requeridos para percibir la pensión completa. En todo caso, se señala que esto requerirá reformas de los sistemas de pensiones, complementados con esfuerzos sustanciales para permitir a los trabajadores mantener su empleabilidad a lo largo de su vida laboral, ofreciéndoles oportunidades adecuadas de reconversión profesional.

Consecuentemente, se presentan las principales propuestas de actuación para asegurar la sostenibilidad de las pensiones, entre ellas: $1^{\circ}$ ) «se trabaje más y durante más tiempo», mediante el aumento de las edades de jubilación -recompensándose a los que se jubilen más tarde y penalizando a los que lo hagan prematuramente-; $2^{\circ}$ ) se calcule la base de la pensión mediante el computo de la media de las bases de cotización de toda la carrera laboral; $3^{\circ}$ ) se limiten o eliminen las jubilaciones tempranas; y $4^{\circ}$ ) se fomente la prolongación de la vida activa del trabajador más allá de la edad ordinaria de jubilación.

Por otro lado, se propone complementar los sistemas públicos de Seguridad Social con planes privados o de capitalización; junto a medidas para proteger de la pobreza a las

\footnotetext{
${ }^{66}$ LIBRO VERDE, en pos de unos sistemas de pensiones europeos adecuados, sostenibles y seguros. SEC (2010) 830,7 de julio de 2010. COM (2010) 365 final.

${ }^{67}$ Países como Dinamarca, Finlandia, Grecia, Holanda, Italia y Portugal ya han implementado medidas de retraso automático de la edad de jubilación en función de lo que aumente la esperanza de vida. Véase: 23. BRAVO FERNÁNDEZ, Carlos y MARTÍN-SERRANO JIMÉNEZ, Enrique. Las reformas de pensiones en Europa: alternativas negociadas vs el modelo del Libro Blanco. LanHarremanak. Revista de relaciones Laborales, núm. 26. 2012, pp. 75-94. P. 87.

${ }^{68}$ Como es el caso de Francia. Ibídem, p. 87.
} 
personas mayores y con medidas de igualdad de género, como puede ser igualar la edad de jubilación de hombre y mujeres ${ }^{69}$.

Por el contrario, en el Dictamen del Comité Económico y Social Europeo sobre el «Libro Verde ${ }^{70}$, y en igual sentido en Dictamen de $2011^{71}$, el Comité Económico y Social Europeo manifiesta no compartir la idea de que el mero aumento de la edad legal de jubilación solucione el problema del envejecimiento demográfico, más bien cree que ello provocará más pobreza o la derivación de estos a pensiones de invalidez, prestaciones de desempleo o a subsidios de mínimos. Proponiendo, que el objetivo debe ser aumentar la edad de jubilación real, incentivando la prolongación de la vida laboral.Además, considera que los mecanismos de aumento automático de la edad de jubilación en función del aumento de la esperanza de vida son peligrosos, ya que deben ser los Parlamentos quienes asuman dicha responsabilidad.

Nuevamente, en el Estudio Prospectivo Anual sobre el Crecimiento: anticipo de la respuesta global de la UE a la crisis de $2011^{72}$; en el Estudio Prospectivo Anual sobre el Crecimiento $2012^{73}$; en el Libro Blanco sobre las pensiones adecuadas, seguras y sostenibles de 2012 74 ; y en el Estudio Prospectivo Anual sobre el Crecimiento 2013 ${ }^{75}$, la Comisión propone que, los Estados miembros que aún no lo hayan hecho, aumenten la edad de jubilación en consonancia con la esperanza de vida. A lo que se añade,en el Libro blanco de 2012, que incrementar la edad de jubilación puede ayudar a mantener o, incluso aumentar, el nivel futuro de las tasas de reemplazo ${ }^{76}$.

En contraposición, el Comité Económico y Social Europeo en su Dictamen de 12 de julio de 2012, al Libro blanco ${ }^{77}$, señala que la prolongación de la edad legal de jubilación «constituye una respuesta al envejecimiento de la sociedad corta de miras» porque podría exponer a muchos pensionistas al riesgo de la pobreza, sin perjuicio de que sea necesario aproximar la edad real de jubilación a la edad legal en vigor, aunque de forma negociada con

\footnotetext{
${ }^{69}$ LIBRO VERDE, en pos de unos sistemas de pensiones europeos adecuados, sostenibles y seguros. SEC (2010) 830 , 7 de julio de 2010. COM (2010) 365 final

${ }^{70}$ En el Dictamen del Comité Económico y Social Europeo sobre el tema «Libro Verde — En pos de unos sistemas de pensiones europeos adecuados, sostenibles y seguros». COM (2010) 365 final. (2011/C 84/08).

${ }^{71}$ Dictamen del Comité Económico y Social Europeo sobre «El futuro del mercado de trabajo en Europa — En busca de una respuesta eficaz a las tendencias demográficas» (Dictamen exploratorio). (2011/C 318/01).

${ }^{72}$ Comunicación de la Comisión al Parlamento Europeo, al Consejo, al Comité Económico y Social Europeo y al Comité de las Regiones. Estudio Prospectivo Anual sobre el Crecimiento: anticipo de la respuesta global de la UE a la crisis. Bruselas, a 12 de enero de 2011 . COM (2011) 11 final, p. 8.

${ }^{73}$ Comunicación de la Comisión. Estudio Prospectivo Anual sobre el Crecimiento 2012. Bruselas, a 23 de noviembre de 2011. COM (2011) 815 final. VOL. $1 / 5$, p. 5 .

${ }^{74}$ Libro Blanco. Agenda para unas pensiones adecuadas, seguras y sostenibles. Bruselas, de 16 de febrero de 2012. COM (2012) 55 final, p. 10 .

${ }^{75}$ Comunicación de la Comisión. Estudio Prospectivo Anual sobre el Crecimiento 2013. Bruselas, 28 de noviembre de 2012. COM (2012) 750 final.

${ }^{76}$ Ibídem, p.6

77 Dictamen del Comité Económico y Social Europeo sobre el «Libro Blanco - Agenda para unas pensiones adecuadas, seguras y sostenibles» [COM (2012) 55 final] (2012/C 299/21). Bruselas, 12 de julio de 2012. DO C219/115 de 4 de octubre de 2012.
} 
los interlocutores sociales, y no mediante mecanismos automáticos que aumenten la edad reglamentaria de jubilación, tal como recomienda la Comisión. Por ello, manifiesta su oposición al aumento de la edad de jubilación reglamentaria y a la modificación de los sistemas de indexación de las pensiones ${ }^{78}$.

\section{LA EDAD DE JUBILACIÓN EN LOS PAÍSES DE LA UE}

Los siguientes datos están obtenidos de la información facilitada por el Sistema de Información Mutua sobre Protección Social (MISSOC) con fecha de 1 de enero de $2014^{79}$, el cual está coordinado por la Comisión Europea, ofreciendo acceso a información detallada, comparable y periódicamente actualizada sobre los sistemas nacionales de protección social en los países de la Unión Europea, más Islandia, Liechtenstein, Noruega y Suiza.

Se analizarán tan solo los datos referidos a la edad ordinaria de jubilación y a la posibilidad de prolongar el trabajo una vez alcanzada ésta, que es el objeto de este estudio.

\section{La edad ordinaria de jubilación en los países de la UE}

La edad ordinaria de jubilación en los países de la Unión Europea no es homogénea, además, en algunos países la edad de jubilación es distinta para los hombres que para las mujeres, aunque la tendencia en todos ellos es equipar la edad de jubilación entre hombres y mujeres e incrementarla de forma progresiva en los próximos años.

Así, entre los países en que actualmente la edad ordinaria de jubilación es distinta en los hombres que en las mujeres se encuentran: Austria (65 años para los hombres y de 60 años para las mujeres; Bulgaria (63 años y 8 meses para los hombres y de 60 años y 8 meses para las mujeres); Croacia (65 años para los hombres y de 61 años para las mujeres);República Checa (62 años y 8 meses para los hombres y 61 años y 8 meses para las mujeres sin hijos; 60 años y 8 meses, si han criado 1 hijo; 59 años y 8 meses, si han sido 2; 58 años y 8 meses, si han sido 3 o 4; y57 años y 8 meses, con 5 o más hijos); Estonia (63 años en los hombres y de 62 años en las mujeres);Italia (En el sector privado es de 66 años y 3 meses para los hombres y de 63 años y 9 meses para las mujeres -64 años y 9 meses en el caso de las trabajadoras por cuenta propia-);Lituania (63 años para los hombres y de 61 años para las mujeres); Malta (Trabajadores nacidos antes del 01 de enero 1952: 61 años para los hombres y de 60 años para

\footnotetext{
${ }^{78}$ En la mayoría de los países las pensiones públicas se actualizan según el incremento de los precios, lo cual, según sus críticos, favorece la espiral inflacionista.

${ }^{79} \mathrm{http}$ ://ec.europa.eu/social/main.jsp?catId=815\&langId=es
} 
las mujeres -con opción a jubilarse a los 61 años-); Polonia (60 años para las mujeres y de 65 años para los hombres); Rumania (59 años y 9 meses para las mujeres, y 64 años y 9 meses para los hombres);y Reino Unido (65 años para los hombres y de 60 años para las mujeres).

Entre éstos países, los que han decidido igualar la edad de jubilación entre hombres y mujeres son: Austria (que la habrá igualado, entre los años 2024 y 2033); Croacia (en donde la edad de jubilación de las mujeres se incrementó gradualmente en 3 meses por año desde 1 de noviembre de 2010, para llegar a 65 años en 2030); República Checa (La edad de jubilación de hombres se incrementa gradualmente en 2 meses por año y la de las mujeres en 4 meses por año -6 meses a partir de 2018- hasta que se iguale a la de los hombres); Estonia (aumentándose gradualmente la edad de las mujeres hasta que en 2016 se iguale en 63 años a la de los hombres); Lituania (aumentando cada año en 4 meses para las mujeres y en 2 meses para los hombres hasta que se iguale en 65 años para las mujeres y los hombres en 2026); Malta (la edad de jubilación se iguala tanto para los hombres como para las mujeres, a partir de los nacidos en 1952); Polonia (desde el 1 de enero de 2013, la edad de jubilación aumentará gradualmente, hasta que llegue a los 67 años para los hombres y las mujeres); Rumania (aumentando a 63 años en la mujeres y a 64 años y 9 meses en los hombres el 1 de enero de 2030, y a 64 años y 9 meses en las mujeres y 65 años en los hombresen 1 de enero de 2015); y Reino Unido (desde el 6 de abril 2010 la edad de pensión estatal de las mujeres está aumentando gradualmente hasta llegar a los 65 años, en noviembre de 2018).

Los países de la Unión Europea en que la edad ordinaria es igual en los hombres y las mujeres son:Hungría y Eslovaquia (en donde la edad ordinaria de jubilación es de 62 años);Bélgica, Chipre, Dinamarca, Luxemburgo, Eslovenia, y Finlandia (65 años para los hombres como para las mujeres); Irlanda y Portugal (66 años,para los hombres como para las mujeres); Francia (depende del año de nacimiento y de si se ha completado el período mínimo de afiliación. Así si se ha completado el período mínimo de afiliación: la edad ordinaria de jubilación de las personas nacidas antes del 01 de julio 1951 es de 60 años aumentándose en cinco meses por año de nacimiento para llegar a 62 para las personas nacidas en 1955 o después. Si el período mínimo de afiliación no se ha completado: la edad ordinaria de jubilación es de 65 años para las personas nacidas antes del 01 de julio 1951, aumentándose gradualmente por año de nacimiento para llegar a los 67 años para las personas nacidas en 1955 o después); Alemania (la edad ordinaria de jubilación es de 67 años, para todos los nacidos después de 1963.Sin embargo, será posible que los asegurados puedan jubilarse a la edad de 65 años sin que sus pensiones se vean reducidas si completan 45 años de cotizaciones obligatorias de empleo, y la atención y de los períodos de crianza de los hijos hasta la edad de 
10 años del niño. También se prevé la jubilación anticipada a los 63 años, sin reducción en la prestación, para aquellos trabajadores nacidos antes de 1952 y que hayan cotizado al menos 45 años); Grecia (67 años, en el caso de contar con 15 años de cotización, y de 62 años, el caso de contar con 40 años de cotización);Letonia (62 años y 3 meses para los hombres como para las mujeres); España (En 2014: 65 años, con 35 años y 6 meses o más cotizados, y 65 años y 2 meses con un período de cotización menor); Suecia (Jubilación flexible desde los 61 años, hasta los 67 años, o más con consentimiento del empleador); y Holanda (65 años y un mes para los hombres como para las mujeres en 2013).

Los países que han decidido incrementar la edad de jubilación son: Bulgaria (que desde el 31/12/2011, se incrementaen 4 meses por año hasta llegar a los 63 años para las mujeres y 65 años de edad para los hombres, aunque en 2014 se suspendió la medida que debía prolongar el incremento progresivo de la edad de jubilación hasta los 67 años); Croacia (a partir de 2031 se incrementarse gradualmente en 3 meses por año hasta llegar a 67 años en 2038); República Checa (a partir de que se iguale la edad entre hombres y mujeres, el aumento será de 2 meses al año); Estonia (a partir de 2017 se continuará el aumento gradual de la edad de jubilación hasta situarse para los hombres y las mujeres en 2026 en 65 años); Italia (Aumentará gradualmente con el incremento de la esperanza de vida. Así en enero de 2021, la edad de jubilación no podrá ser inferior a 67, y llegará a 69 y 9 meses en el año 2050); Lituania (aumentando cada año en 4 meses para las mujeres y en 2 meses para los hombres hasta que se iguale en 65 años en 2026); Malta (62 años para los nacidos durante los años 1952 a 1955; 63 años para las personas nacidas durante los años 1956 a 1958; 64 años para las personas nacidas durante los años 1959 a 1961; 65 años para las personas nacidas en 1962 o después);Polonia (desde el 1 de enero de 2013, la edad de jubilación aumentará gradualmente, hasta que llegue a los 67 años para los hombres y las mujeres); Rumania (aumentando a 63 años en la mujeres y a 64 años y 9 meses en los hombres el 1 de enero de 2030, y a 64 años y 9 meses en las mujeres y 65 años en los hombres en 1 de enero de 2015); Reino Unido (a partir de diciembre 2018 la edad de jubilación, tanto para hombres como para las mujeres comenzará a aumentar hasta llegar a los 66 años en octubre de 2020); Hungría (se ha incrementado gradualmente desde el año 2010, llegando a los 65 años en 2022 para los nacidos en 1957 y después);Alemania (se prevé que aumente gradualmente hasta los 67 años desde 2012 hasta 2029, a partir de los nacidos en 1947); Letonia (la edad legal de jubilación se incrementa gradualmente en 3 meses por cada año hasta llegar a 65 años en 2025); Portugal (a partir de 2014 la edad normal de jubilación varía de acuerdo con el promedio de vida a la edad de 65 años);Eslovaquia (desde 2017 en adelante la edad legal de jubilación se 
incrementará gradualmente en función del crecimiento de la esperanza de vida); España (desde el 1 de enero de 2013 la edad de jubilación se incrementa progresivamente cada año hasta 2027, en que la edad ordinaria de jubilación será de 65 años, con 38 años y 6 meses de cotización; o de 67 años, con menos de 38 años y 6 meses de cotización); y Holanda (a partir de 2013, la edad legal de jubilación se incrementará gradualmente hasta llegar a los 66 años en 2019 y a los 67 años en 2023. A partir de 2024, la edad legal de jubilación estará vinculada a la esperanza de vida).

\section{La posibilidad de prolongar el trabajo tras cumplir la edad ordinaria de jubilación en los países de la UE}

En algunos países es posible aplazar el momento de jubilarse y seguir trabajando tras haber alcanzado la edad ordinaria de jubilación. Para incentivarlo, algunos países de la Unión Europea aplican porcentajes adicionales sobre la base de la prestación, lo que permite mejorar la cantidad inicial de la pensión en el momento en que se acceda a ella.

Así países como Austria, Bulgaria, República Checa, Estonia, Finlandia, Francia, Alemania, Grecia, Hungría, Letonia, Luxemburgo, Malta, Polonia, Portugal, Eslovaquia, España, Reino Unido y Suecia no establecen límite alguno de edad para trabajar tras haber alcanzado la edad ordinaria de jubilación.

Otros países permiten el trabajo más allá de la edad ordinaria de jubilación, pero con límites temporales. Así,Croacia permite el aplazamiento hasta los 70 años (5 años), siempre que el beneficiario haya completado los 35 años de cotización y que no haya accedido anteriormente a la jubilación; Chipre permite el aplazamiento hasta la edad de 68 años; Dinamarca permite el aplazamiento hasta 120 meses en cualquier momento después de la edad de jubilación, aunque en el caso de la pensión complementaria sólo es posible hasta llegar a la edad de 75 años; Italia permite el retraso en la edad de jubilación hasta los 70 años y 3 meses (ajustado según la esperanza de vida); Lituania permite el retraso en la edad de jubilación hasta cinco años.

En sentido contrario, países como Bélgica, Irlanda, Rumania y Holanda no sólo no incentivan el trabajo tras alcanzar la edad ordinaria de jubilación, sino que además no permiten el aplazamiento en la jubilación.

Por otro lado, entre los países de la Unión Europea que incentivan el retraso en la jubilación, mejorando la cuantía de la pensión inicial, se encuentran: Austria, en dondese incentiva la prolongación del trabajo tras haber alcanzado la edad legal de jubilación, 
incrementando el porcentaje a aplicar a la base de la prestación, desde el 1 de enero de 2005, en un $4,2 \%$ por año de aplazamiento, hasta un máximo de $12,6 \%$; en Bulgaria se incrementa la pensión mediante un $4 \%$ adicional por año trabajado tras haber alcanzado la edad de jubilación, siempre que tengan completados los requisitos exigidos para adquirir el derecho a una pensión y no se haya accedido a ella; en Croacia el incrementoes del 0,15\% por cada mes de aplazamiento, con un incremento máximo del $9 \%$ en un período de 5 años de aplazamiento; en Chipre la pensión de jubilación se incrementa en un 0,5\% por cada mes de aplazamiento; en la República Checa la pensión dejubilación se incrementa en un 1,5\% de la base reguladora por cada 90 días de aplazamiento; en Dinamarca la pensión se incrementa con un porcentaje calculado sobre principios actuariales de acuerdo a la longitud de aplazamiento; en Estonia el importe de la pensión de vejez se incrementa en un $0,9 \%$ por cada mes de retraso en la jubilación; en Finlandia la cuantía de la pensión se incrementa en un 0,6\% por cada mes que se trabaje tras la edad de 65 años (pensión nacional) o un 0,4\% por cada mes más allá de los 68 años (de pensiones relacionadas con las retribuciones); en Alemania algunas pensiones de jubilación pueden incrementarse en un $0,5 \%$ por cada mes de aplazamiento en la edad normal de jubilación; en Grecia se incrementa las pensiones de jubilación en un 3,3\% adicional por cada año trabajado entre los 65 y los 68 años, siempre que se cuente con al menos 35 años de carrera de cotización; en Hungría la pensión de jubilación se incrementa en un $0,5 \%$ de la pensión por cada 30 días de tiempo de servicio adicional; en Italia se mejora los coeficientes según el total de años cotizados hasta un máximo de 40 años; en Lituania la pensión se incrementa en un $8 \%$ por cada año completo de retraso en la jubilación más allá de la edad ordinaria de jubilación, aunque con el límite de 5 años; en Portugal la pensión se incrementa multiplicando la tasa mensual por el número de meses de cotización cumplidos entre la edad de 66 y el mes en que comienza la pensión, con un límite máximo fijado en la edad de 70 años. La tasa de bonificación mensual varía entre $0,33 \%$ y $1 \%$ de acuerdo con el número de años de cotización cumplido en el en el que comienza la pensión; en Eslovaquia se incrementa la pensión en un 0,5\% por cada 30 días de retraso en la edad de jubilación; en Eslovenia se incrementa en 1\% por cada año adicional después de haber cumplido las condiciones requeridas de 60 años de edad y 40 años de período de cotización; en España el trabajador puede continuar trabajando después de la edad de jubilación, suspendiéndose ésta. La tasa que se aplica a la base de cálculo se incrementa entre un $2-4 \%$ por cada año completo de cotización adicional acreditado entre la edad legal de jubilación y la jubilación efectiva, de acuerdo con la siguiente escala:hasta 25 años de contribución: 2\%; entre 25 y 37 años: 2,75\%; a partir de 37 años: un 4\%; en Suecia los 
derechos de pensión pueden acumularse, siempre y cuando sigua trabajando y cotizando. En el antiguo sistema la pensión complementaria anual se puede incrementar de forma permanente en un $0,7 \%$ de la pensión de vejez por mes trabajado después de la edad de 65 años y hasta la edad de 70 años; en el Reino Unido las pensiones de jubilación Estatales se incrementan en aproximadamente un 10,4\% por cada año de retraso en la edad de jubilación; en Francia los períodos de actividad más allá de la edad para recibir una pensión completa (60 a 62 años de edad) producen un aumento de la cuantía de la pensión (bono) de acuerdo con el número de trimestres adicionales de actividad (el 1,25\% desde el año 2009). Entre las edades de 65 y 67, el asegurado que no cumpla con el período de seguro requerido dependiendo de su de nacimiento, se beneficiarán de un aumento de la duración del seguro en un 2,5\% por trimestre adicional que trabaje tras alcanzar la edad ordinaria de jubilación; y en Rumania no se prevé aplazamiento en la edad de jubilación, sin embargo en el método de cálculo se prevé un incremento fijo del 0,5\% después de la edad normal de jubilación.

En Malta, Letonia o Polonia trabajar tras alcanzar la edad ordinaria de jubilación no produce directamente una pensión más alta, aunque puede producir una pensión más alta indirectamente (a través del pago de las contribuciones adicionales y mediante el incremento de la base reguladora).

Otros países como Bélgica, Irlanda y Holanda no sólo no incentivan el trabajo tras alcanzar la edad ordinaria de jubilación, sino que además no se permite el aplazamiento en la jubilación.

Finalmente, en Luxemburgo, no se incrementa la pensión, pero si la persona está activa más allá de los 65 años de edad, las cotizaciones pagadas por el asegurado se devuelven al final del año.

\section{LA EDAD DE JUBILACIÓN DE BRASIL}

\section{Regulación de la edad de jubilación en Brasil}

En Brasil, la primera manifestación legislativa sobre esta materia fue la aprobación de la Ley Eloy Chaves, Decreto Legislativo 4682 de 24 de enero de 1923, por el que se crea el Plan de Jubilaciones y Pensiones para los ferroviarios, para queposteriormente se extendiera a todos los trabajadores que hubieran computado, por lomenos, treinta años de servicio y 
cincuenta de edad; o proporcionalmenteal trabajador que había logrado solamente cumplir uno de los requisitos, oel tiempo de servicio y la edad mínima exigida por la ley ${ }^{80}$.

Posteriormente, debido a la proliferación de sistemas de jubilaciones y pensiones vinculados a lasempresas y a grupos de trabajadores específicos que originaron pequeños regímenesde pensiones,llevó el Estado a reestructurar elsistema nacional de pensiones, creándose los Institutos Nacionales de jubilación.

Tras la promulgación de la Ley Orgánica de Previsión Social de1960, la jubilación ordinaria comenzó a ser llamada de jubilaciónpor tiempo de servicio, exigiéndose que el trabajador hubiera completado 35 o 30 años de servicios, además de tener como mínimo55 años de edad, y no cincuenta años como se exigía en la épocade las Cajas de Pensiones. Sin embargo, dos años después, el requisito de edad mínima fue eliminado por la Ley 4.130/62, no exigiéndose ninguna edad mínima para tener derecho a la jubilación si se cumplía con uno de los dos períodos de servicios requeridos ${ }^{81}$. Posteriormente, el Decreto-Ley $N^{\circ} 66$ de 1966, introdujo la necesidad de un periodo mínimo de carencia, es decir, un mínimo de cotizaciones al sistema para que los asegurados pudieran disfrutar la prestación de jubilación.

La Constitución de la República Federativa de Brasil, de 1988,consagra el principio constitucional de universalidad de la cobertura, asegurando que las prestaciones de sustituciónde la renta del trabajo no serían menoresal salario mínimo, con revalorización periódica de ésta.

Posteriormente, la Ley N 9.717/1998 y la Enmienda Constitucional 20, de 15 de diciembre de 1998 -complementado y mejorado por la reforma de la Enmienda Constitucional $\mathrm{N}^{\circ}$ 41/2003-,extingue la jubilación por tiempo de servicio, y crea lajubilación por tiempo de cotización, dando una nueva redacción al artículo 201 de la Constitución, en el que se exige para tener derecho a la prestación de jubilación, un periodo mínimo de 35 años de cotización para los hombres y de 30 años para las mujeres; y en general, tener cumplidos los 65 años, para los hombres, y 60 años, para las mujeres, con reducción de cinco años para el caso de los trabajadores rurales de ambos sexos, y para los que ejercensus actividades en régimen de economía familiar, incluyendo el agricultor, el minero y el pescador; todo ello con unas reglas transitorias.

La Ley $N^{\circ 9.876 / 99}$ también tuvo en cuenta la introducción de la edad en que el trabajador accede a la jubilación para determinación de la base de cálculo de la prestación, de forma que a menor edad se acceda a ella, menor será la cuantía de ésta, lo que se expresa en el

\footnotetext{
${ }^{80}$ BIER, Clerilei. La evolución de la Seguridad Social en Brasil y la jubilación por tiempo de cotización. En: VV.AA. La reforma de las

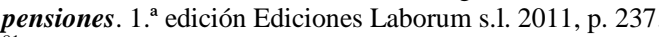

${ }^{81}$ Ibídem, p. 239
} 
llamado "factor previdenciario", el cual se calcula teniendo en cuenta la esperanza de vida del trabajador en el momento de la jubilación (elemento reductor), su edady los períodos $\operatorname{cotizados}^{82}$.

\section{Futuras medidas relacionadas con la edad de jubilación}

Como se puede comprobar, en Brasil también, desde finales del siglo XX, preocupa el incremento del gasto en pensiones, lo que puede suponer un déficit financiero insostenible y difícil de controlar, y mucho más teniendo en cuenta que la esperanza de vida en Brasil está aumentando como en el resto de países, aunque se sitúa algo menor que en España, pero eso sólo supone padecer los mismos problemas unos años más tarde. De hecho, el índice de sostenibilidad de las pensiones a largo plazo de Allianz ${ }^{83}$, sitúa a Brasil en el puesto 49 entre los 50 países analizados, por tanto, solo Tailandia se sitúa en un puesto peor en cuanto a sostenibilidad de las pensiones, y en donde España ocupa el puesto 39. Los motivos que llevan a Brasil a encontrarse en tal nivel de riesgo de déficit, son: $1^{\circ}$ ) el previsible incremento de la población mayor; $2^{\mathrm{a}}$ ) el que a pesar de que la edad de jubilación se situé en 65 años, en muchos casos se pueden jubilar con 35 o 30 años de $\operatorname{servicios}^{84}$; y $3^{\circ}$ ) que la tasa de sustitución aún es bastante alta, lo que supone una fuerte presión para el sistema de pensiones.

Una de las primeras medidas que puede abordar Brasil es igualar la edad de jubilación de hombre y mujeres, no sólo porque los motivos que llevaron a establecer una edad menor en las mujeres, ya no se dan en la actualidad, sino que, como consecuencia de lo primero, deviene discriminatoria una edad de jubilación distinta entre hombres y mujeres, si ésta ya no se fundamenta en alguna justificación objetiva y razonable ${ }^{85}$.

Pero aun así, en el futuro se deberá implementar alguna política que garantice la sostenibilidad del sistema de pensiones, que puede ser algunas de las adoptadas en Europa, $\mathrm{u}$ otra distinta. De hecho, el "factor previdenciario" es una medida similar al"factor de sostenibilidad" en España, que supone otro mecanismo de ajuste automático que vincula la

\footnotetext{
${ }^{82}$ Ibídem, p. 245.

${ }^{83} 2014$ Pension Sustainability Index.International. Pension Papers 1/2014. Allianz SE. https://www.allianz.es/drvg07sf/AZS_Site_Allianz/Home/prensa/Temas-de-

Interes/Analisis_e_investigacion/Enlace\%20An\%C3\%A1lisis\%20e\%20Investigaci\%C3\%B3n/2014\%20pensiones.pdf, p.6.

${ }^{84}$ En 2012, la edad media de jubilación era de 54,97 años en los hombres y de 52,01 en las mujeres. DA SILVA PEREIRA, Eduardo. Evolução das Idades Médias de Concessão e dos Tempos Médios de Contribuição das Aposenta dorias por Tempo de Contribuição Concedidas entre 1996 e 2012. Informe de Previdência Social. Ministério da Previdência Social. Brasília-DF. junho/2013. Volume 26. Número 6, p. 6.

${ }^{85}$ Según señala el Tribunal Constitucional, en Sentencia (Pleno) 22/1981, de 2 de julio de 1981 (RTC 1981 22 ), Fj. $3^{\circ}$ : “....toda desigualdad no constituye necesariamente una discriminación. El artículo 14 del Convenio Europeo - declara el mencionado Tribunal en varias de sus sentencias - no prohibe toda diferencia de trato en el ejercicio de los derechos y libertades: la igualdad es sólo violada si la desigualdad está desprovista de una justificación objetiva y razonable, y la existencia de dicha justificación debe apreciarse en relación a la finalidad y efectos de la medida considerada, debiendo darse una relación razonable de proporcionalidad entre los medios empleados y la finalidad perseguida".
} 
cuantía inicial de la pensión de jubilación, entre otros, al incremento de laesperanza de vida, con el objeto de ajustar las pensiones iniciales a la baja, si la esperanza de vida del trabajador aumenta, o si éste se jubila tempranamente. Aunque en ambos casos implica reducir la tasa de sustitución.

Consecuentemente, sería más efectivo exigir siempre una edad mínima para tener derecho a la prestación de jubilación, sin perjuicio de otros requisitos de cotización -eliminando completamente la jubilación por tiempo de servicio-, y ajustar la edad de jubilación en relación con el incremento de la esperanza de vida, sin actuar en otros parámetros, que como en los casos analizados en los países europeos, producen reducciones significativas de la tasa de sustitución. En cualquier caso, se debe evitar introducir alguna de las reformas propuestas en Brasil para migrar de un sistema de reparto a uno de capitalización $^{86}$, aunque este no sea privado, sino de gestión gubernamental, el cual, además de ser totalmente insolidario, no garantiza unas prestaciones seguras y suficientes para los futuros pensionistas, ni siquiera con ese control del gobierno, como lo ha demostrado la actual crisis financiera mundial y la pérdida de rentabilidad en los últimos años de productos financieros vinculados a planes de pensiones, como la incapacidad de los Estados para impedirla.

\section{CONCLUSIONES}

1. Es indudable que el envejecimiento de la población crea tensiones en los sistemas de pensiones públicos de reparto, y se ha demostrado que la jubilación anticipada tiene efectos negativos en la sostenibilidad financiera de los sistemas de pensiones, pero existen otros factores adicionales que desempeñan también un papel importante en la situación financiera del sistema de pensiones, como es el nivel de ingresos del sistema de pensiones y la productividad $^{87}$, además de una mejor gestión del Sistema y un control muy riguroso del fraude fiscal y de la Seguridad Social.

2. La sostenibilidad de los sistemas de pensiones público depende del aumento del empleo y la prolongación de la edad de jubilación ${ }^{88} ;$;así, actualmente, la presión sobre el

\footnotetext{
${ }^{86}$ GUTIERRE NOGUEIRA, Narlon. O equilíbrio financeiro e atuarial dos rpps: de princípio constitucional a política pública de estado. Informe de Previdência Social. Ministério da Previdência Social. Brasília-DF. Março/2012. Volume. Número 3, p. 11.

${ }^{87}$ MINGORANCE ARNÁIZ, Ana Cristina y GARCÍA HERRADOR, Agustín. Análisis empírico del efecto que la jubilación anticipada tiene sobre el gasto en pensiones. Presupuesto y Gasto Público, número 48/2007: 59-84. Secretaría General de Presupuestos y Gastos 2007, Instituto de Estudios Fiscales, p. 66.

${ }^{88}$ VIGNON, Jerôme. La protección social: una cuestión de interés común para Europa dentro del marco de la nueva estrategia de Lisboa. Revista del Ministerio de Trabajo y Asuntos Sociales. Seguridad Social. Seminario sobre la reforma de la Seguridad Social en tiempos de estabilidad y crecimiento económico. Santander 2005, pp. 21-28, p. 25.
} 
sistema de pensiones es más debido a la falta de empleo e inversión que al envejecimiento ${ }^{89}$ demográfico. Sin embargo, en unos momentos de crisis económica, la cual provoca un fuerte crecimiento de la población desempleada; una caída de los ingresos públicos en cotizaciones a la Seguridad Social, debido a la destrucción de puestos de empleo y una caída en la recaudación en impuestos debido a la caída del consumo y de la actividad económica, irremediablemente, todo ello provoca una reducción en los ingresos y un aumento en los gastos públicos, y de la Seguridad Social en concreto, ésta última, además, presionada por el aumento del número de pensionistas y la caída de cotizantes.

3. El actual sistema público de pensiones no es actualmente viable si no se ajusta a los continuos cambios ${ }^{90}$.Es preciso gestionar las repercusiones sobre las finanzas del sector público y la economía en general, asegurando la estabilidad financiera del sistema y la viabilidad económica general, y para ello hay que adecuar ${ }^{91}$ la edad de jubilación a la esperanza de vida, lo cual reduce el número de pensiones, y por tanto, el coste para el sistema, además de dar oportunidad a seguir contribuyendo al sistema. Es por ello que desde la UE parece claro que debe plantearse ya no sólo el acercar la edad real de jubilación a la ordinaria, eliminándose las jubilaciones anticipadas que no estén justificadas, sino que debe plantearse la necesidad de promover el trabajo más allá de la jubilación y de incrementar la edad legal de jubilación, todo ello acompañado de medidas como la formación, adecuación de los puestos y condiciones de trabajo y de la conciliación familiar y laboral, entre otras.

4. En el futuro, aun en ciclos de crecimiento económico y de relativo pleno empleo, deberá darse respuesta a una nueva realidad social en donde habrá más trabajadores con mayor edad que tendrán capacidad para trabajar, de los cuales no podemos prescindir, y un menor número de jóvenes que engrosarán la población activa y que, además, deberán soportar el coste de las pensiones de un creciente número de pensionistas, a lo cual hay que añadir que la inmigración ya no puede ser la solución prioritaria, aunque sí complementaria.

5. Dado que la edad de jubilación está configurada en los diversos estados de la Unión Europea de forma distinta y en el marco de diferentes sistemas de protección social, con peculiaridades propias y realidades sociales particulares, la respuesta a la sostenibilidad de los sistemas públicos de pensiones, no es aconsejable ni adecuado dar una respuesta para

\footnotetext{
${ }^{89}$ MORENO ROMERO, Francisca. Políticas de empleo y pensiones en la Unión Europea y su impacto en las reformas españolas. Estudios Financieros. Recursos Humanos. Comentarios y Casos Prácticos, núm. 356. Noviembre 2012, pp. 121-164. P. 153.

${ }^{90}$ GARCÍA NINET, José Ignacio. Sobre la revisión del Pacto de Toledo y las propuestas del Gobierno de España de 29 de enero de 2010 para la sostenibilidad del Sistema de Protección Social: algunas cuestiones. Tribuna social: Revista de seguridad social y laboral. 2010. Número 232, p. 12.

${ }^{91}$ En este sentido, la UE define la «adecuación» como la interrelación de dos objetivos que deben garantizar las pensiones de jubilación, que son: evitar que el trabajador que se jubila esté abocado a la pobreza y, ayudar a que quienes han trabajado, sigan manteniendo cierto nivel de vida después de la jubilación. FISCHER, George. Los objetivos comunes en materia de Protección Social de la UE: Modernización y reforma de los sistemas de pensiones. Revista del Ministerio de Trabajo y Asuntos Sociales. Seguridad Social. Número extraordinario, 2007. Seminario «Seguridad Social: protección y cohesión social». Santander 2006, pp. 27-48, p. 27.
} 
toda la Unión Europea ${ }^{92}$, como sería fijar una edad de jubilación única para todos los estados, que aunque deseable, muy posiblemente aún no sea factible. El incremento de la edad de jubilación, y la igualación de ésta entre hombres y mujeres, ambos realmente necesarios, debe realizarse en cada estado de la Unión Europea de forma que se adecue a la situación de cada uno, aunque no retrasándola innecesariamente.

6. No puede olvidarse afrontar la cuestión de la pobreza en la vejez, que aún ahora sigue siendo un problema acuciante en muchos países y que la actual crisis ha agudizado, debiéndose asegurar unas rentas mínimas, prestaciones sanitarias y asistencia social, por ello debe evitarse que la tasa de sustitución entre pensión y rentas caiga excesivamente; es mucho más deseable trabajar más años, que jubilarse antes con unas pensiones de miseria.Entre las distintas políticas adoptadas en la Unión Europea para asegurar la sostenibilidad de los sistemas de pensiones, sólo el incremento de la edad ordinaria de jubilación, consigue el objetivo de sostenibilidad del sistema sin reducir la tasa de sustitución entre pensión y salario.

7. Finalmente, todo parece indicar que la fuente del problema actual de sostenibilidad de los sistemas públicos de pensiones no es tanto el envejecimiento demográfico, sino más bien se debe, como apunta la Comisión ${ }^{93}$, a la incapacidad de las políticas actuales para adaptarse a la nueva situación demográfica.

\footnotetext{
${ }^{92}$ GARCÍA VIÑA, Jordi. ¿Cómo afecta la crisis económica a los modelos actuales europeos de Seguridad Social? En: El Futuro Europeo de la Protección Social. Murcia: Laborum, 2010, p. 94.

${ }_{93}$ Comunicación de la Comisión de 12 de octubre de 2006: El futuro demográfico de Europa: transformar un reto en una oportunidad. COM (2006) 571 final, p. 14
} 